\title{
Mesanenin Nadir Benign Neoplazmı: Mesane Leiomyomu
}

\author{
Rare Benign Neoplasm of the Bladder: Leiomyoma of the Bladder
}

\author{
Dursun BABA ${ }^{1}$ \\ (D) 0000-0002-4779-6777 \\ Ekrem BAŞARAN ${ }^{1}$ \\ (D) 0000-0001-8319-512X \\ Muhammet Ali KAYIKÇI ${ }^{2}$ \\ (1) 0000-0001-9567-0661
}

\begin{abstract}
ÖZ
Mesanenin benign mezenşimal lezyonları oldukça nadirdir ve tüm mesane tümörlerinin \%15 'inin oluştururlar. Bunların içinde de en sık leiomyoma saptanmaktadır. Benign lezyonlar radyolojik olarak maling kitleleri taklit etmesi nedeniyle klinik öneme sahiptir. Tanı radyolojik tetkiklerle kitlenin saptanması ve sonrasında yapılan cerrahi eksizyon ya da biyopsi ile histopatolojik olarak konulmaktadır. Ekstravezikal ve intramural form sistoskopik olarak saptanamayabilirken intravezikal leiomyomlar sistoskopi ile saptanabilir. Sistoskopi sırasında mesane içinde protrüde, kısmen düzgün sınırlı ve yüzeyi mesane mukozası ile kaplı lezyonlar görüldüğünde mesane leiomyomu ayırıcı tanıda düşünülmelidir. 44 yaşında kliniğimize irridatif semptomlarla tarafımıza başvuran ve mikroskopik hematüri saptanan erkek hastada mesanede $2 \times 2 \mathrm{~cm}$ kitle saptand. Minimal invaziv tedavi (TUR-mesane) sonrasında leiomyoma tanısı konulan vaka sunulmaktadır.

Anahtar kelimeler: Leiomyom; mesane.
\end{abstract}

\begin{abstract}
Benign mesenchymal lesions of the bladder are very rare and constitute 1-5\% of all bladder tumors. Among these, leiomyoma is the most common. Benign lesions are clinically important because they mimic radiologically malign masses. The diagnosis is made histopathologically by detecting the mass by radiological examinations and subsequent surgical excision or biopsy. Extravesical and intramural forms may not be detected cystoscopically, while intravesical leiomyomas can be detected by cystoscopy. Bladder leiomyoma should be considered in the differential diagnosis when protruding, partially smoothly bound and covered bladder mucosa lesions are observed during cystoscopy. A 44-year-old male patient who presented to our clinic with irridative symptoms and was found to have microscopic hematuria and $2 \times 2 \mathrm{~cm}$ mass in the bladder. A case of leiomyoma diagnosed after minimally invasive treatment (TUR-bladder) is presented.

Keywords: Leiomyoma; bladder.
\end{abstract}

\section{GİRIŞ}

Mesanenin benign mezenşimal lezyonları oldukça nadirdir ve tüm mesane tümörlerinin \%1-5'ini oluşturmakla birlikte en sık leiomyoma saptanmaktadır (1-3). Klinik semptomlar tümörün bulunduğu yer ve büyüklügüne bağlı olarak obstriktif ya da irritatif semptomlar, hematüri ile farklı şekillerde karşımıza çıkabildiği gibi aynı zamanda lezyonlar insidental olarak da saptanabilir (1-4). Mesane leiomyomları yerleşimine göre ekstravazikal, intramural ve intravezikal olarak sınıflandırılabilir ve çoğunlukla da intravezikal saptanır $(3,5,6,8)$. Tanıda ultrason, bilgisayarlı tomografi (BT), manyetik rezonans görüntüleme (MR) ve intravenöz pyelografi (IVP) kullanılabilir.

Geliş Tarihi / Received : 25.07.2019

Kabul Tarihi / Accepted : 17.09.2019

Çevrimiçi Yayın Tarihi /

Available Online

: 07.11.2019 
Tanı kitlenin görüntüleme yöntemleri ya da sistoskopik olarak saptanmasından sonra dokunun histopatolojik incelenmesi sonrasında konulmaktadır. Tedavi cerrahi olmakla birlikte kitlenin yeri ve büyüklüğüne göre açık ya da endoskopik olarak uygulanabilir (1-7). Biz de bu çalışmada ultrasonografi ve BT'de belirlenen kitleye transüretral rezeksiyon uyguladığımız ve sonrasında patoloji raporu ile mesane leiomyomu saptanan vakayı sunmayı amaçladık.

\section{OLGU SUNUMU}

Kırk dört yaşında erkek hasta yan ağrısı ve urgency şikayetleri ile kliniğimize başvurdu. Yapılan tetkiklerde mikroskobik hematüri saptand. Bunun üzerine hastaya abdomino-pelvik ultrasonografi yapıldı ve bu incelemede mesane sağ posterolateralinde sağ üreter alt uca uyan alanda lümene protrüde kistik $2 \times 2 \mathrm{~cm}$ görünüm izlendi (üreterosel?). Bunun üzerine hastaya kontrastlı abdomen BT görüntülemesi istendi ve mesane sağ yan duvarda 10x14 mm boyutunda kontrastlanan polipoid hiperdens lezyon tespit edildi (Resim 1).

$\mathrm{Bu}$ gelişmeler sonrasında hastaya endoskopik işlem yapılmasına karar verildi ve sistoskopide; üretra doğal, sağ orifisin posteriorunda mesane sağ yan duvar arka duvar bileşkesinde $2 \mathrm{~cm}$ 'lik düzgün yüzeyli lümene protrüde solid lezyon gözlendi (Resim 2). Sağ orifis ve geri kalan mesane mukozası normaldi. Hastanın mesanesindeki lezyona 2017 yılı Ekim ayında transüretral rezeksiyon uyguland1 (Resim 3) ve intraoperatif, postoperatif komplikasyon gözlenmedi. Operasyon sonrasında 2. gün üretral kateter çekilerek hasta taburcu edildi. Hematoksilen-Eozin (H\&E) ile yapılan histopatolojik incelemede düzgün sınırlı nodüler yapılanmalar oluşturan, birbirini çaprazlayan kalın demetler halinde düz kas fasikülleri dikkati çekti (Resim 4). Ayrıca yapılan immünohistokimyasal incelemede de fusiform, künt uçlu ve birbirini çaprazlayan demetler teşkil eden düz kas hücrelerinin epitelyal membran antijeni negatif, desmin ve düz kas aktini pozitif boyand. Histomorfolojik bulgular leiomyom lehine değerlendirildi. Postoperatif sistoskopik ve radyolojik kontrollerde mesane normal olarak değerlendirildi. Hastadan vaka sunumu amaçlı bilgilendirilmiş olur için onam alındı.

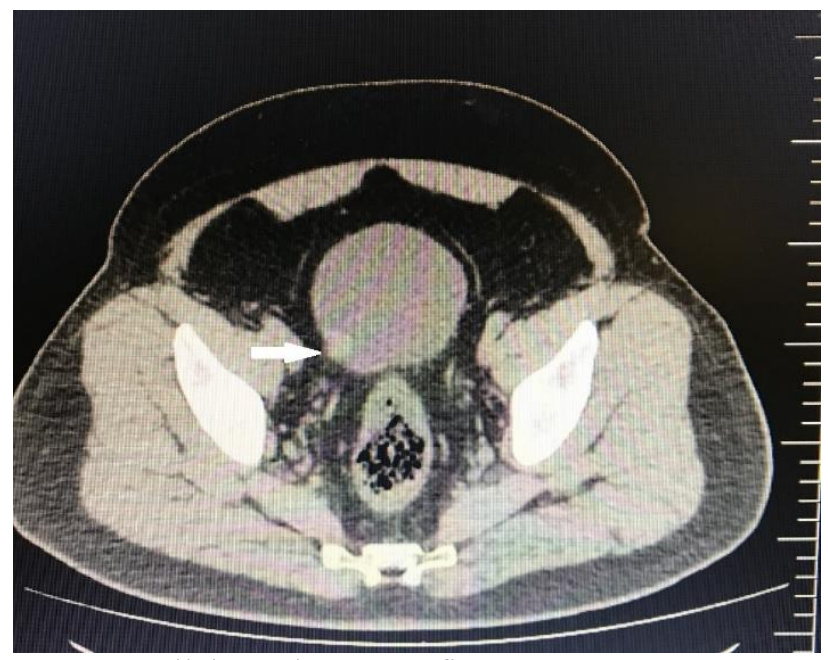

Resim 1. Bilgisayarlı tomografi görüntüsü

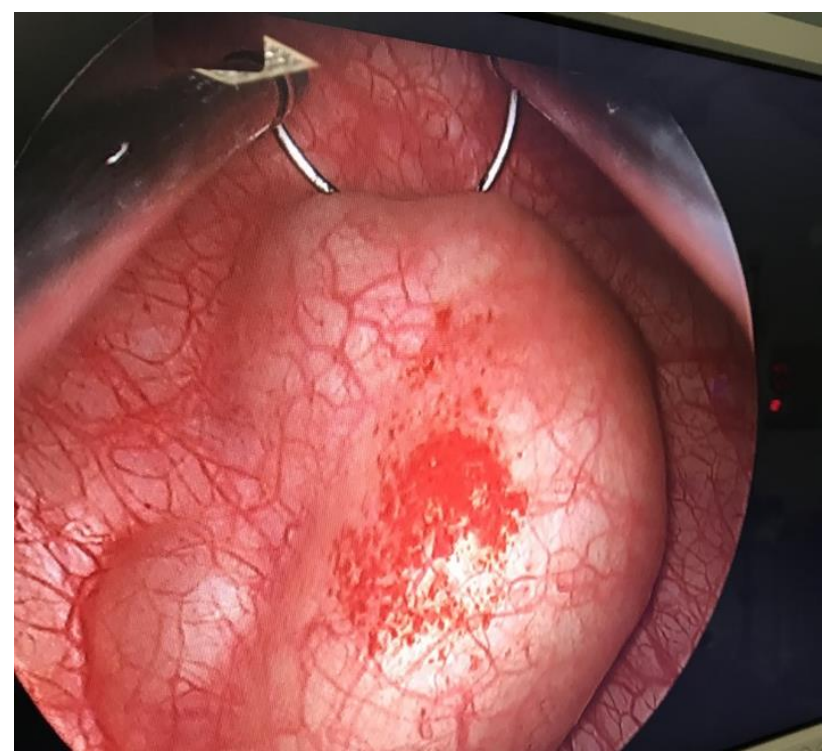

Resim 2. Sistoskopik görüntü

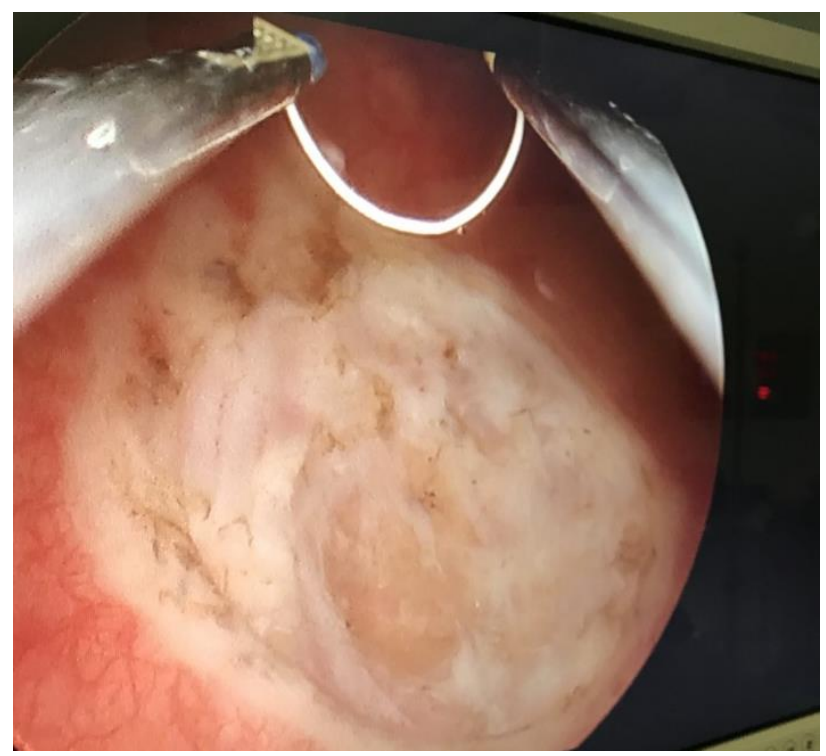

Resim 3. Rezeksiyon sonrası görüntü

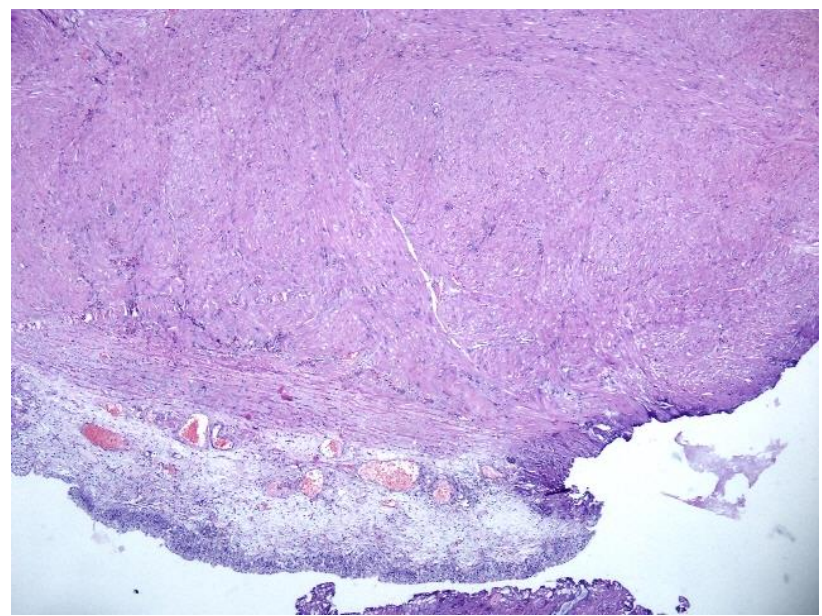

Resim 4. Histopatolojik incelemede düzgün sınırlı nodüler yapılanmalar oluşturan, birbirini çaprazlayan kalın demetler halinde düz kas fasikülleri dikkati çekti (H\&E, x40) 


\section{TARTIŞMA}

Leiomyom mesanenin benign mezenșimal tümörüdür (17). Benign lezyonlar kitle görüntüsü nedeniyle histopatolojik tanı konularak malign lezyonlardan ayrılmalıdır. Mesanenin benign mezenşimal kitleleri; myomlar, fibromlar, angiomlar, miksomlar ve leiomyomlar olarak sayılabilir (2). Literatürde 250 civarında mesane leiomyomu olgusu saptanmıştır (8).

Campbell ve Gislason (3) tarafindan leiomyom; benign mesane lezyonları arasında en sık görülen tip olarak belirtilmiștir. Jiang ve ark. (9) tarafından leiomyomun en fazla depolama semptomları ile prezente olurken neredeyse üçte birlik kısmı asemptomatik olarak rapor edilmiştir.

Goluboff ve ark. (10) 37 vakayı inceledikleri literatür taramasında leiomyomun kadınlarda ve 4. dekatta daha sık saptandığını belirtmişlerdir. Yine aynı çalışmada \%63 intravezikal ve en sik semptom obtstriktif semptomlar olarak bildirilmiştir. Park ve ark. (7) tarafından sunulan 9 hastalık seride tüm hastalar kadın olarak saptanmıştır. Fakat Knoll ve ark. (11) 5 vakalık çalışmalarında irritatif semptomların daha sık görüldüğünü bildirmişlerdir.

Bizim sunduğumuz vakada hastanın yan ağrısı ve irridatif semptomları mevcut ve hasta cinsiyeti erkekti. Tanı radyolojik tetkiklerle kitlenin saptanması ve sonrasında yapılan cerrahi eksizyon ya da biyopsi ile histopatolojik olarak konulmaktadır. IVP, ultrason, BT, MR yöntemleri tanı koymada önemli yardımcı tetkiklerdir. İntravezikal form sistoskopik olarak tek, normal mesane mukozasıyla kaplı olarak görülebilirken ekstravezikal ve intramural form sistoskopik olarak saptanamayabilir (11). Bizim vakamızda da sistoskopi de benzer görüntü görüldü.

Bizim vakamızda şikayetleri takiben ilk olarak ultrasonografi yapılmıștır ve ön tanı olarak üreterosel düşünülmüştür. Ardından yapılan kontrastlı abdominopelvik BT'de mesane arka duvarda kontrastlanan solid kitlenin görülmesiyle birlikte kesin tanı spinal anestezi altında gerçekleştirilen sistoskopi ve devamında transüretral rezeksiyon ile konulmuştur. En fazla vaka sayısına sahip Goluboff ve ark. (10) tarafindan yapılan çalışmada hastaların \%87'sinde tanının sistoskopik olarak konulduğu belirtilmiştir. Tedavi cerrahi olmakla birlikte cerrahinin şekli, tümörün boyutu ve yeri, üreter orifisleri ve sfinkter ile olan ilişkisine bağlı olarak değişkenlikler gösterebilir. Boyut olarak göreceli küçük intravezikal leiomyom transüretral rezeksiyon ile eksize edilebilirken, büyük kitleler, üreter orifisi ile ilişkili ya da intramural, ekstravezikal kitleler için en iyi seçenek açık parsiyel rezeksiyon ya da enükleasyondur $(11,12)$.

Cerrahi tedavi seçenekleri ile ilgili olarak Silva-Ramos ve ark. (13) tarafından yapılan çalışma iyi bir örnektir. Bu çalışmada 90 olgu değerlendirilmiş olup vakaların \%62,2'sine açık cerrahi, \%30'una TUR, \%5,6'sına ise transvajinal rezeksiyon yapılarak tedavi edildiği bildirilmiştir.
Sonuç olarak literatürde henüz mesane leiomyomunun malign dönüşümü saptanmadığı için semptomatik hastalarda tedavinin amac1; semptomları hafifletmek ve malign kitleleri ekarte etmektir. Sistoskopi sırasında mesane içinde protrüde, kısmen düzgün sınırlı ve yüzeyi mesane mukozası ile kaplı lezyonlar görüldüğünde mesane leiomyomu ayırıcı tanıda düşünülmelidir. Malign kitlenin dışlanması amacıyla kitleden biyopsi ya da cerrahi eksizyon ile alınan dokunun histopatolojik incelemesi yapılmalıdır. Böylelikle hem hastanın lezyondan kaynaklanan şikayetlerine yönelik tedavi yapılırken ayrıca malign lezyon tanısı da ekarte edilmiş olacaktır.

\section{KAYNAKLAR}

1. Soloway D, Simon MA, Milikowski C, Soloway MS. Epithelioid leiomyoma of bladder: An unusual cause of voiding symptoms. Urology. 1998;51(6):1037-9.

2. Sundaram PC, Rawal A, Saltzman B. Characteristics of bladder leiomyoma as noted on magnetic resonance imaging. Urology. 1998;52(6):1142-3.

3. Campbell EW, Gislason GJ. Benign mesothelial tumors of the urinary bladder: Review of literature. $\mathrm{J}$ Urol. 1953;70(5):733-41.

4. Fekkak H, Moufid K, Jounal A, el Mrini M, Benjelloun S. Leiomyoma of the urinary tract. Ann Urol (Paris). 2001;35(1):47-50.

5. Deliveliotis C, Giannakopoulos S, Zougri S, Kostakopoulos A, Kastriotis J. Leiomyoma of the bladder: A case report. Int Urol Nephrol. 1998;30(2):141-3.

6. Fernández Fernández A, Mayayo Dehesa T. Leiomyoma of the urinary bladder floor: Diagnosis by transvaginal ultrasound. Urol Int. 1992;48(1):99-101.

7. Park JW, Jeong BC, Seo SI, Jeon SS, Kwon GY, Lee HM. Leiomyoma of the urinary bladder: A series of nine cases and review of the literature. Urology. 2010;76(6):1425-9.

8. Gok A. Transurethral resection of a large urinary bladder leiomyoma: a rare case report. Urol J. 2017;14(4):4052-4.

9. Jiang $\mathrm{XZ}, \mathrm{Xu} \mathrm{C}$, Zhang $\mathrm{NZ}, \mathrm{Xu} \mathrm{ZS}$. Influence of clinical characteristics and tumor size on symptoms of bladder leiomyoma: a pooled analysis of 61 cases. Chin Med J (Engl). 2012;125(14):2436-9.

10. Goluboff ET, O'toole K, Sawczuk IS. Leiomyoma of bladder: Report of case and review of literature. Urology. 1994;43(2):238-41.

11. Knoll LD, Segura JW, Scheithauer BW. Leiomyoma bladder. J Urol. 1986;136(4):906-8.

12. He L, Li S, Zheng C, Wang C. Rare symptomatic bladder leiomyoma: case report and literature review. J Int Med Res. 2018;46(4):1678-84.

13. Silva-Ramos M, Massó P, Versos R, Soares J, Pimenta A. Leiomyoma of the bladder. Analysis of a collection of 90 cases. Actas Urol Esp. 2003;27(8):581-6. 